\title{
Vascular Shunt Thrombosis
}

National Cancer Institute

\section{Source}

National Cancer Institute. Vascular Shunt Thrombosis. NCI Thesaurus. Code C111652.

The presence of a thrombus within a vascular shunt. 